\title{
Synthesis of monodispersed barium sulphate nanoparticles using water-benzene mixed solvent
}

\author{
V. Ramaswamy ${ }^{a^{*}}$, R.M. Vimalathithan ${ }^{a}$, V. Ponnusamy ${ }^{b}$ \\ ${ }^{a}$ Department of Physics, Annamalai University, Annamalai Nagar 608002, India \\ ${ }^{b}$ Department of Physics, MIT campus, Anna University, Chennai, India
}

*Corresponding author: E-mail: srsaranram@ rediffmail.com

Received: 09 April 2011, Revised: 18 May 2011 and Accepted: 01 June 2011

\section{ABSTRACT}

Precipitation is a hopeful process for nanoparticle production due to rapid expedient, highly economic and uncomplicated. Barium sulphate nanoparticles were prepared through precipitation process via barium chloride and sodium sulphate as the reagents in water-benzene reaction medium. Eight different compositions of mixed solvents, including pure water, 20 vol. $\%$, 30 vol. $\%, 50$ vol. $\%, 70$ vol. \%, 80 vol. \%, 90 vol. \% and 95 vol. \% of benzene were practiced. The effects of the volume percentage of benzene in the aqueous medium on the resultant barium sulphate nanoparticles were scrutinized. The products were characterized through X-ray diffraction (XRD), Field Emission Scanning Electron Microscopy (FESEM) with Energy Dispersive X-ray Spectrum (EDX) and Fourier Transform Infrared Spectroscopy (FTIR) techniques. The synthesized nanoparticles are well dispersed and they exhibit an orthorhombic structure and spherical in morphology with an average size of $35.9 \mathrm{~nm}$. From this we establish, water-benzene mixed solvent inhibits barium sulphate nucleation growth. Copyright (C) 2011 VBRI press.

Keywords: Barium sulphate nanoparticles; precipitation; water- benzene; FESEM.

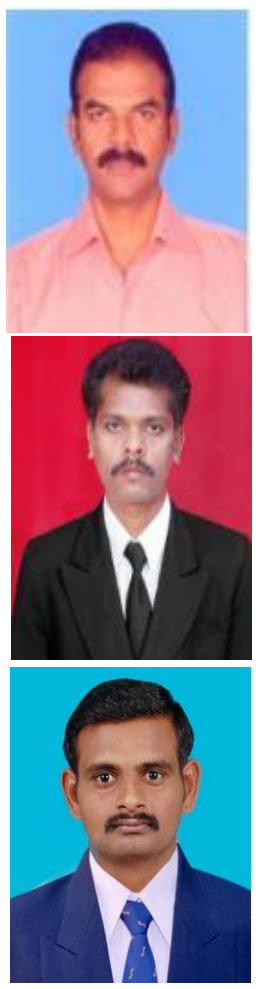

V. Ramaswamy is currently working as professor in Department of physics, Annamalai University, Tamilnadu, India. He did his B.Sc., Physics in GVN College, Kovilpatti, Tamilnadu, India. He completed his M.Sc., Physics at Annamalai University, Tamilnadu, India. He did his Ph.D in the area of Applied Spectroscopy at Annamalai University. His area of interest includes "Spectroscopy", "Radioactivity", "Luminescence" and "Nanoscience".

V. Ponnusamy is presently working as an Associate Professor in Department of Physics, MIT Campus, Anna University, India, He did his B.Sc., Physics in Vivekananda College, Tiruvadagam West, Madurai. He completed his post graduation in Physics at Annamalai University, Tamilnadu, India. He did his Ph.D in the area of Solid State Luminescence with IGCAR collaboration at Annamalai University Tamilnadu, India.

R.M. Vimalathithan obtained his B.Sc., Physics from Salem Sowdeswari College, Periyar University, Salem. He completed his Post Graduation in Physics at Annamalai University, Tamilnadu, India. At Present (2011), he is doing Ph.D in the topic "Thermoluminescence studies in Sulphate Nanomaterials" in Collaboration with IGCAR at Department of Physics, Annamalai University, Tamilnadu, India

\section{Introduction}

The synthesis of inorganic materials with nanometer size, controlled surface properties and controlled morphology attract increasing interest recently due to its significant applications in various fields. Barium sulphate, which is commonly referred to as barite, is desirable for several uses on account of its high specific gravity, opaqueness to Xrays, inertness and whiteness. It has been panoptically utilized in industrial applications such as paper coatings, filler in plastics and pigments in paint. They may also applied in the studies of biomineralization, molecular recognition, and pharmaceutical formulations. Rather than it is a very good thermoluminescence material, which is used in radiation dosimeter purposes [1-6]. Such a crucial nano particles have been synthesized through the chemical method. The chemical synthesis method has numerous advantages such as trouble free technique, inexpensive, not as much of instrumentation, great possibility of doping and bulky quantities of materials can be obtained. Several chemical methods have been proposed in the past to produce the nanoparticles, like precipitation [7], taylorcouette reactor [8], T-mixers [9], membrane reactors [10] micro emulsion system $[\mathbf{1 1}, \mathbf{1 2}]$ and so on. Among these, 
precipitation is the delightful method due to its straight forward procedure, easy of mass production and demand less apparatus. However, there is difficulty in precipitation synthesis for controlling the size, size distribution and aggregation of the resultant particles. It is significant to research for an effective means to trouble shoot the application of precipitation. The exercise of a mixed solvent is, doubtlessly a novel approach in materials synthesis and processing [13]. Nevertheless, there are only limited studies dealing with the formulation of nanoscale materials in the mixed solvent method.

In this work, water-benzene mixed solvents have been puzzled out to synthesize barium sulphate nanoparticles in the precipitation method. To understand the effectual control of barium sulphate size in the nanometer range and without aggregation, whatever we gestate in the precipitation method is achieved by interchanging the volume percentage of benzene in the water-benzene mixed solvent.

\section{Experimental}

\section{Materials}

The reactants such as barium chloride, sodium sulphate and benzene were used without any further purification. Deionized water was utilized as solvent in this method. The precipitation reaction follows as:

$$
\mathrm{BaCl}_{2}(\mathrm{aq})+\mathrm{Na}_{2} \mathrm{SO}_{4}(\mathrm{aq}) \rightarrow \mathrm{BaSO}_{4}(\mathrm{~s})+2 \mathrm{NaCl}(\mathrm{aq})
$$

\section{Precipitation and procedure}

In this study, two processes were followed to precipitate barium sulphate nanoparticles, which are:

(1) Precipitation in water and

(2) Precipitation in mixed solvent (water-benzene).

As per the precipitation in the deionized water, $50 \mathrm{ml}$ of $0.1 \mathrm{M} \mathrm{Na}_{2} \mathrm{SO}_{4}$ solution was added drop wise with equal quantity of $\mathrm{BaCl}_{2}$ solution under vigorous stirring using magnetic stirrer for half an hour at room temperature and it is kept stable until the precipitation is obtained. Finally, the precipitate was collected and washed with various solvents for several times. It was dried in the hot air oven at $100^{\circ} \mathrm{C}$ for 12 hours and was taken to the characterization process.

In the case of precipitation in the mixed solvent, seven different compositions (20 vol. \%, 30 vol. \%, 50 vol. \%, 70 vol. $\%, 80$ vol. $\%, 90$ vol. $\%$ and 95 vol. \%) of benzenewater were taken. Barium chloride and sodium sulphate were generally soluble in water but insoluble in benzene which makes benzene as a suitable anti-solvent, as further addition of benzene in the solution, it lowers the solubility of reagents and thus generates the super saturation. The solubility circumstance of reagents was an important viability of this method. For example, 95 vol. \% of water benzene mixed solvent composition, barium chloride and sodium sulphate was taken in the molar ratio as prepared for precipitation in water (for all the various compositions were followed in the same molar concentration for both reagents). To begin with, both the reagents were dissolved in the 95 vol. \% of benzene in water mixed solvents separately. Then, the sodium sulphate mixed solvent solution was added by drop wise (drop wise means less amount of reactant flowed per unit of time, this extending to lower supersaturation) to the barium chloride mixed solvent solution under vigorous stirring for half an hour at room temperature and kept stable for complete precipitation. Subsequently, the collected precipitate was washed with various solvents for several times and the particles were oven dried at $100^{\circ} \mathrm{C}$ for 12 hours in air atmosphere. Same procedure was followed for all other compositions of mixed solvent system and finally, dried samples were taken for the characterization process.

\section{Methods}

The synthesized samples were characterized by different techniques, viz, XRD, FESEM-EDX, and FTIR.The structure and average crystalline size were determined by $\mathrm{X}$-ray diffractogram. The X-ray pattern of the powdered sample were recorded at room temperature using XPERTPRO PAN alytical with a curved graphite crystal diffracted monochromater, with a source of $\mathrm{Cu}_{\alpha}\left(\lambda=1.5406 \mathrm{~A}^{\circ}\right)$ at $40 \mathrm{kV}$ and $30 \mathrm{~mA}$, Ni filter and $\mathrm{NaI}(\mathrm{T} 1)$ scintillation detector cooled by liquid nitrogen. During the recording of the diffractrogram, a narrow silt of $0.1 \mathrm{~mm}$ was used with a scanning speed of $1 / 2^{\circ}$ per min and a time constant of $2 \mathrm{~s}$. The sample was firmly pressed into an aluminum holder, with an area of $30 \mathrm{~mm} \times 30 \mathrm{~mm}$. The diffraction patterns were obtained over the $2 \theta$ values in the region $20^{\circ}-50^{\circ}$.

The morphology and the size of the barium sulphate particles were examined with FESEM (Hitachi SU6600) by an accelerating voltage of $15 \mathrm{kV}$. The spot size in FESEM is smaller than in the conventional SEM and it can produce very high resolution images (better than three to six times of the conventional SEM). The identification of elemental composition using EDX spectrum which is also recorded with FESEM instrument.

FTIR analysis was carried out to identify the functional group present in the samples: the powdered sample was mixed with $\mathrm{KBr}$ at various ratios 1:10, 1:20, 1:30, 1:40, and 1:50. The pellets were prepared and FTIR spectra were recorded. The maximum absorption and large number of peaks are observed for the samples in the ratio of 1:30 (sample: $\mathrm{KBr}$ ) and chosen for further analysis. The Perkin Elmer RX1 series FTIR spectrometer was used for recording the IR spectra of the sample. The instrument wavenumber ranges from 4000 to $400 \mathrm{~cm}^{-1}$ with an accuracy of $\pm 0.01 \mathrm{~cm}^{-1}$ and resolution of $\pm 4 \mathrm{~cm}^{-1}$. The instrument was calibrated with the spectra of a standard polystyrene film at room temperature. Every time, before the spectrum of the sample was recorded; the spectrum of the polystyrene film was obtained and checked for the accuracy and transmittance.

\section{Results and discussion}

\section{$X$ - Ray diffraction (XRD)}

Fig. 1. shows the X-ray diffraction pattern of barium sulphate particles for seven different compositions of 
water-benzene mixed solvents and without benzene (pure water). All the reflection plains are readily matched with a orthorhombic phase of pure barium sulphate, which are basically in good agreement with the reported values (JCPDS card no. 76- 0214) with crystalline cell constants a $=8.898, \mathrm{~b}=5.980$ and $\mathrm{c}=7.155$, space group $\mathrm{P}_{\mathrm{nma}}$. It is also observed that no interaction is taking place with the nature of barium sulphate for the various concentrations of benzene. Only barium sulphate peaks are observed in the XRD spectra and this strongly infers that benzene can only modulate the physical properties of the reaction medium without changing the reaction paths and arrangements of the crystal structure. This proves that the product had high purity in nature. The synthesized barium sulphate demonstrate the diffracted lines with broadening, implies that the crystallites are in nanometer range. The crystalline sizes are calculated using Scherer's formula [14] for the five high intensity peaks observed at $25.95^{\circ}, 26.95^{\circ}, 28.82^{\circ}$, $42.54^{\circ}$ and $42.88^{\circ}(2 \theta)$ with hkl values (210), (102), (211), (113), and (312), respectively.

$$
D=\frac{0.94 \lambda}{\beta \cos \theta}
$$

where, $\mathrm{D}$ - diameter of the crystal, $\lambda$ - X-ray wavelength, $\beta$ - half width of the peak (full width at half maximum) and $\theta$ - Bragg's diffraction angle. Calculated crystalline sizes of various compositions are presented in Table 1. Fig. 2 exhibits the graphical representation between the various composition of water - benzene (\%) and the average particle size from the XRD result.

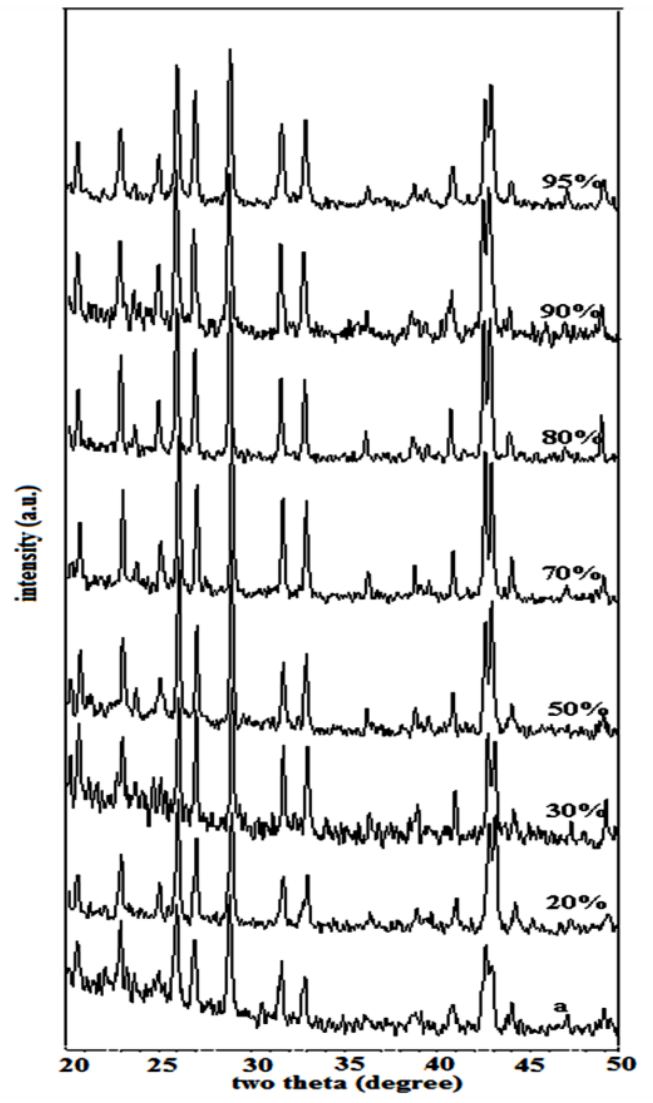

Fig. 1. X-ray diffraction pattern of barium sulphate nanoparticles for pure water (a) and seven different compositions.
From the Table 1 and Fig. 2 the particle size is increased up to 80 vol. \% of mixed solvents and then it is decreased for 90 and 95 vol.\%. Even though the 90 and 95 vol. \% of mixed solvent system is having minimum size, 95 vol. \% of water-benzene mixed solvent system has selected as best concentration in the process of barium sulphate nanoparticle formation from water-benzene system. Since, the crystalline sizes are almost similar for all the reflection planes compared to the reflection planes of 90 vol. \% mixed solvent system.

Table 1. The crystalline sizes of various composition of pure water and mixed solvents.

\begin{tabular}{ccccccc}
\hline \multicolumn{2}{c}{ Particle sizes for various reflection plains } & Average \\
Composition of & & & & & \\
crystalline \\
Benzene - water
\end{tabular}

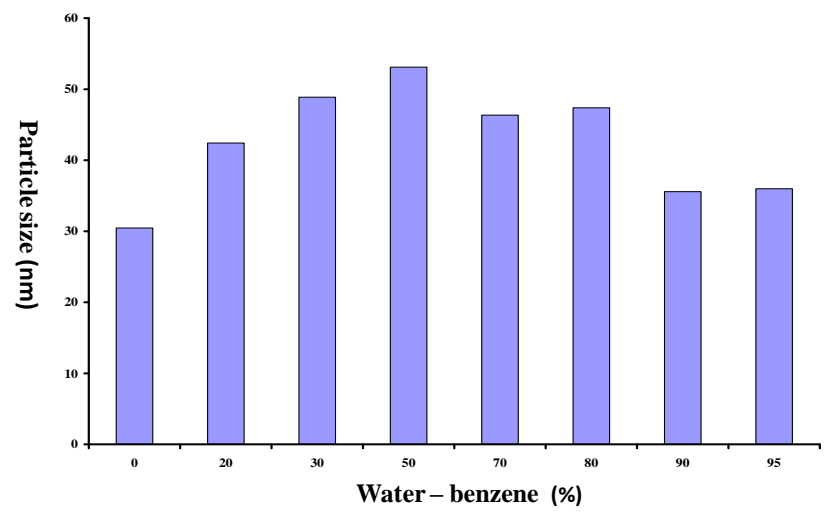

Fig. 2. The particle size distribution of different compositions of water benzene mixed solvent system.

\section{Field Emission Scanning Electron Microscopy (FESEM)}

Fig. 3 (a and b) show the FESEM images of particles synthesized through pure water system and from the images, we could identify the morphology of the particles 
are in spherical shape with agglomeration. The average sizes of the particles range from 20-35 nm.

Insert Fig. 4 (a and b)

To overcome the particle agglomeration, an effective method of mixed solvent process was chosen. Fig. 4 (a and b) show the FESEM images of particles synthesized through the mixed solvent system (95 vol. \%) at various magnifications. From these images, it is clear that the particles have the morphology of spherical shape and the size in the range of $30-40 \mathrm{~nm}$. In this case the particles sizes are slightly increased and is also observed that the particles are homogeneously distributed without agglomeration compared to the former case.
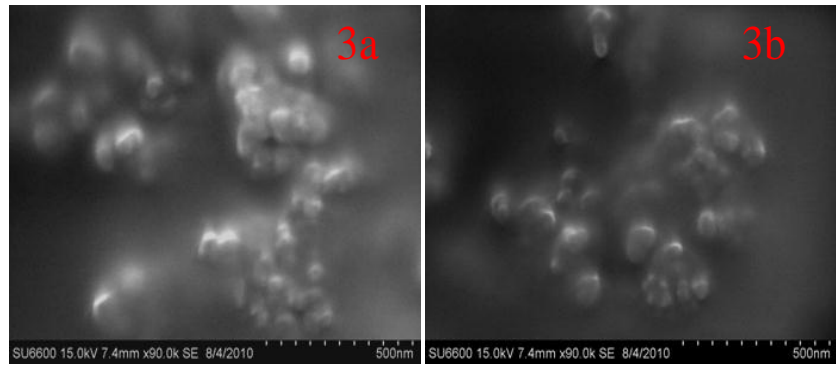

Fig. 3. (a and b) FESEM images of $\mathrm{BaSO}_{4}$ nanoparticle using pure water in precipitation.
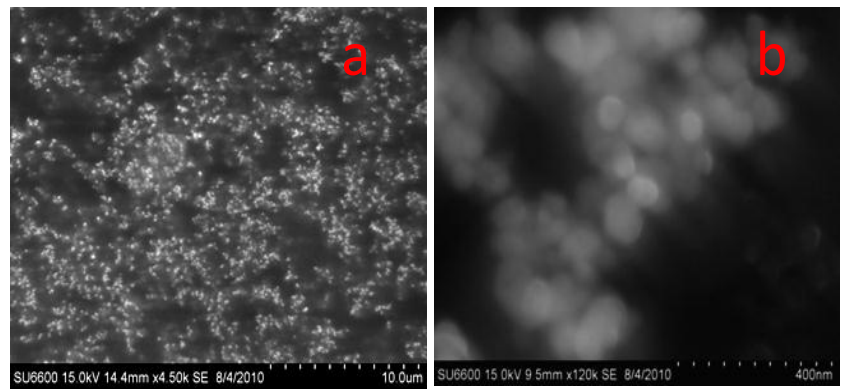

Fig. 4. (a and b) FESEM images of $\mathrm{BaSO}_{4}$ nanoparticles using water benzene ( 95 vol. \%) mixed solvent system at different magnification. (a) $\times 4.50 \mathrm{k}(\mathrm{b}) \times 120 \mathrm{k}$.

Fig. 5 shows the EDX spectrum of barium sulphate nanoparticles synthesized by 95 vol. \% mixed solvent composition. It reveals that the particles have of $\mathrm{Ba}, \mathrm{S}$ and $\mathrm{O}$ elements only. The weight percentage of elemental composition is $60.58 \%$ (Barium), $12.31 \%$ (sulphur) and $27.10 \%$ (oxygen).

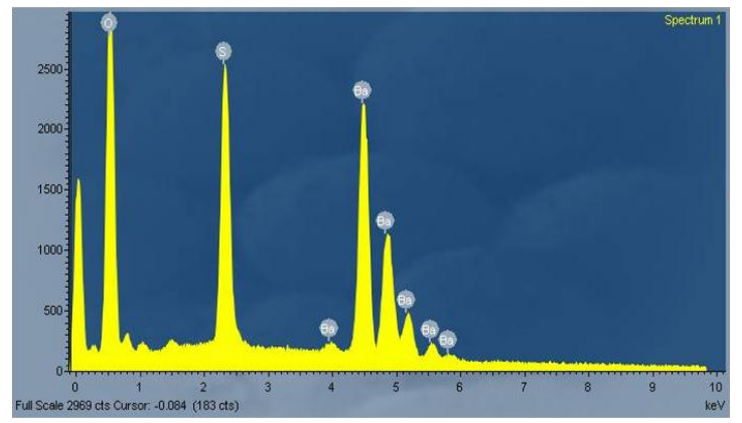

Fig. 5. The EDX spectrum of $\mathrm{BaSO}_{4}$ nanoparticles synthesized by 95 vol. $\%$ of water - benzene system.
Fourier Transform Infrared (FTIR)

Fig. 6a and b demonstrate the FTIR spectrum of barium sulphate nanoparticles using pure water and mixed solvent (95 vol. \%). According to A.S. Povarennykh [15], the sulphate group is having the frequency of vibration of broad band centered at the region of $1200-1080 \mathrm{~cm}^{-1}$. In the case of precipitation in pure water, the broad band centered at $1204-1076 \mathrm{~cm}^{-1}$ and a shoulder at $983 \mathrm{~cm}^{-1}$ are due to the symmetrical vibration of sulphate group. But in the case of mixed solvent system, the broad band of sulphate group in the region of $1192-1077 \mathrm{~cm}^{-1}$ and a shoulder peak at $983 \mathrm{~cm}^{-1}$ are observed. A slight shift in the peak position may be attributed to the interaction of benzene with pure barium sulphate but this interaction is not observed in the XRD pattern. Also the broadening of the sulphate region is sharpened compared to the pure water which may be due to the homogeneous growth of the particles in the mixed solvent. According to Yuhua shen et al [16], the peaks obtained in both cases at $641 \mathrm{~cm}^{-1}$ and $609 \mathrm{~cm}^{-1}$ are due to the out of plane bending vibration of sulphate. The weak absorption band at $2925 \mathrm{~cm}^{-1}$ and $2852 \mathrm{~cm}^{-1}$ could be assigned to the symmetric and asymmetric vibrations of $-\mathrm{CH}_{2}$ and $-\mathrm{CH}_{3}$ groups. The absorption peaks appeared at $3420 \mathrm{~cm}^{-1}$ and $1636 \mathrm{~cm}^{-1}$ are owing to the stretching and deformation of absorbed water molecule.

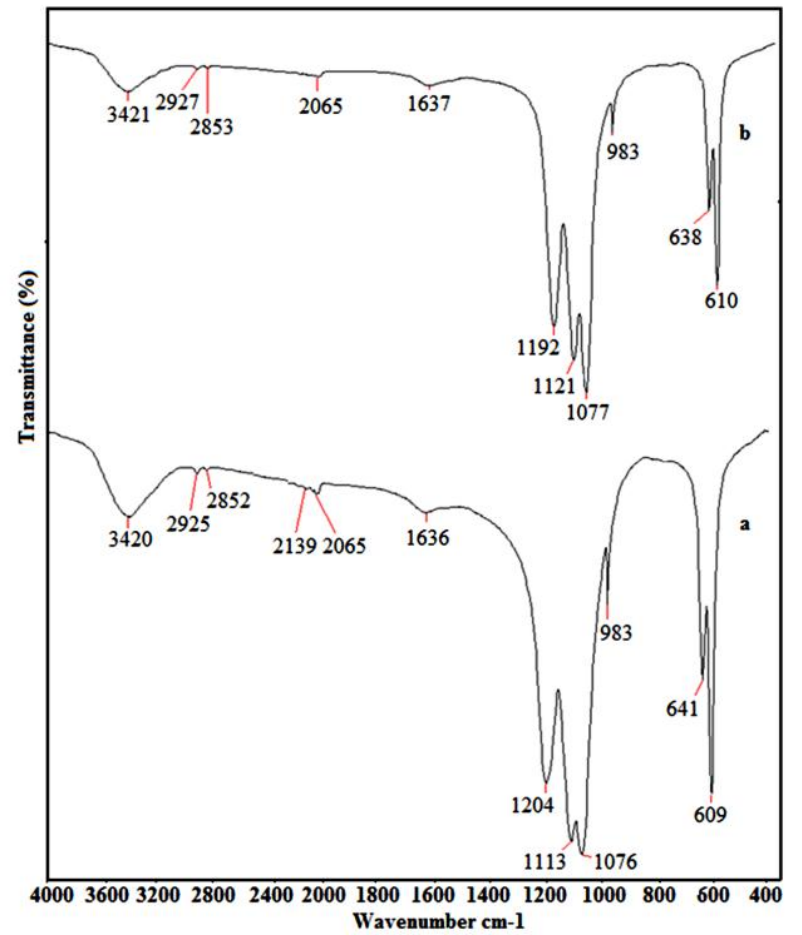

Fig. 6. The FTIR spectra of $\mathrm{BaSO}_{4}$ nanoparticles (a) pure water and (b) mixed solvent water - benzene (95 vol. \%).

In the mixed solvent system, the hydroxyl group of the water content in the prepared sample is reduced. It is confirmed through the decrease in the peak intensity at $3421 \mathrm{~cm}^{-1}$ in the Fig. 6. (a). According to Mann and Das [17], the peaks around $2000 \mathrm{~cm}^{-1}$ are overtones and combination bands of the sulphur-oxygen stretching and bending vibrations. These peaks do not affect the 
identification of the substance involved in the experiment. Without any additional vibrational bands the Fig. 6 (b) is well matched with the Fig. 6 (a).

\section{Conclusion}

Barium sulphate nanoparticles were synthesized using precipitation in pure water (with agglomeration) and waterbenzene mixed solvent (without agglomeration) system. The XRD study exposed that the particles are in orthorhombic structure of pure barium sulphate and the optimum concentration of mixed solvent is sterilized. The average size of the particles obtained in pure water is 30.4 $\mathrm{nm}$ and in the case of mixed solvent system it is $35.9 \mathrm{~nm}$. From the FESEM image, the particle morphology is in spherical shape in both cases, but agglomeration is inhibited in mixed solvent system compared to the precipitation in pure water. The sizes of the particles are also in well agreement with the XRD study. From EDX spectrum, it is confirmed that the presence of $\mathrm{Ba}, \mathrm{S}$ and $\mathrm{O}$ elements are in the surface of the synthesized particles. FTIR study reveals the presence of sulphate group in the synthesized nanoparticles. Thus, from the above different characterizations, mixed solvent method is one of the best and easy way of approach for synthesis of mono dispersered (homogenous and well dispersed) nanomaterials. This mixed solvent method may be used as an alternative for polymer in the synthesis process which is very much applicable in the industrial oriented purpose.
6. Li, M.; Mann, S. Langmuir. 2000, 16, 7088. DOI: $10.1021 / \mathrm{la} 0000668$

7. Yoshikawa, Y.; Nancollas, G.H.; Barone, J. J. Cryst. Growth. 1984, 69, 357. DOI: $10.1016 / 0022-0248(84) 90342-7$

8. Judat, B.; Kind, M. J. colloid interf. Sci. 2004, 269, 341. DOI: $10.1016 /$ j.jis. 2003.07.047

9. Schwarzer, H.-C.; Peukert, W. Chem. Eng. Technol. 2002, 25, 657. DOI: $10.1002 / 1521-4125(200206) 25: 6<657$ : AIDCEAT657>3.0.CO; 2-5

10. Chen, G.G.; Luo, G.S.; Xu, J.H.; Wang, J.D. Powder Technol. 2004 139, 180. DOI: $10.1016 /$ j.powtec. 2003.12 .003

11. Ivanova, N.I.; Rudelev, D.S.; Summ, B.D.; Chalykh, A.A. Colloid J. 2001, 63, 714 . DOI: $10.1023 / \mathrm{A}: 1013267702613$

12. Adityawarman, D.; Voigt, A.; Veit, P.; Sundmacher, K. Chem. Eng. Sci. 2005, 60, 3373 . DOI: $10.1016 /$ j.ces.2004.12.050

13. Lv, Y.; Wu, X.; Wu, D.; Huo, D.; Zhao, S. Powder technol. 2007, $173,174$. DOI: $10.1016 /$ j.powtec.2006.12.018

14. Nagaraja, B.M.; Abimanyu, H.; Jung, K.D.; Yoo, K.S. J. Colloid interf. Sci. 2007, 316, 645.

DOI: $10.1016 / \mathrm{j} . j \mathrm{jis} .2007 .09 .004$

15. Povarennykh, A.S. Am. Mineral. 1978, 63, 956.

16. Shen, Y.; Li, C.; Zhu, X.; Xie, A.; Qiu, L.; Zhu, J. J. Chem. Sci. 2007, 119, 319.

17. Manam, J.; Das, S. Indian J. Pure Ap. Phy. 2009, 47, 435.

\section{Reference}

1. Qi, L.; Ma, J.; Chen, H.; Zhao, Z. Colloid Surface A. 1996, 108, 117. DOI: $10.1016 / 0927-7757(95)$ 03317-3

2. Unsworth, J.; Lunn, B.A.; Innis, P.C.; Mapson, M. J. Mater. Sci. Lett. 1993, $12,132$.

DOI: $10.1007 / \mathrm{BF} 00819937$

3. Molnar, Sz.; Pukanszky, B.; Hammer, C.O.; Maurer, F.H.J. Polymer. 2000, 41, 1529.

DOI: $10.1016 /$ S0032-3861 (99) 00305-5

4. Mann, S. Nature. 365, 1993, 499. DOI: $\underline{10.1038 / 365499 \mathrm{a} 0}$

5. Heywood, B.R.; Mann, S. Adv. Mater. 1994, 6, 9. DOI: $10.1002 /$ adma. 19940060103

\section{Advanced Materials Letters}

\section{Publish your article in this journal}

ADVANCED MATERIALS Letters is an international journal published quarterly. The journal is intended to provide top-quality peer-reviewed research papers in the fascinating field of materials science particularly in the area of structure, synthesis and processing, characterization, advanced-state properties, and applications of materials. All articles are indexed on various databases including $\underline{\mathrm{DOAJ}}$ and are available for download for free. The manuscript management system is completely electronic and has fast and fair peer-review process. The journal includes review articles, research articles, notes, letter to editor and short communications.

Submit your manuscript: http://amlett.com/submitanarticle.php 